\title{
Synthisophy - Integrating the Wisdoms of History into Present Culture (Part 2 - Summary of Chapter 16 through 30)
}

Andre Houle

Chicopee, Massachusetts, USA

\begin{abstract}
The current paper discusses the concept of synthisophy. Synthisophy is defined as the scientific integration of knowledge and wisdom derived from the study of history into the present culture. The paper provides a philosophical view on contemporary sociopolitical issues in the USA and reviews Chapters 16 through Chapter 30 of the original book on synthisophy. The paper's conclusions contribute to the current state of understanding of sociopolitical affairs exploring various theories such as human evolution, political polarization, neuroreality, and brain function.
\end{abstract}

Keywords: Synthisophy, Political polarization, Neuroreality, Philosophical theory, Integration of history into culture, Politics and society

\section{Introduction}

In 1995 an article published in SKOLE, the Journal of Alternative Education, the word synthisophy first appeared (Houle 1995). The word synthisophy then appeared in the Cyclopedic Education Dictionary (Spafford, Pesce and Grosser 1998). After the election of Donald Trump in 2016, I thought it was time to write a book, perhaps better described as an extensive research paper, about synthisophy (Houle, 2021). Here is a summary of Chapters 16 through 30.

\section{Synthisophy and Mission}

Synthisophy - the scientific integration of knowledge and wisdom derived from the study of history into present culture.

\section{Roots - Synthesis/History/Sophy}

Synthesis - the integration of separate material or abstract entities into a single or unified whole History - what has happened in the past; a detailed description of past events as relating to a particular people, country, period, etc...

Sophy - Greek root: wisdom, knowledge; an intellectual system embraciknowledge and truth; study of the real world based on fact and truth, science

The mission of synthisophy is to depolarize the Nation. Citizens are the crux of democracy, an educated and well informed citizenry is vital for the survival of a democratic republic. As Benjamin Franklin said after exiting the Constitutional Convention and was asked what sort of government the delegates had created, his answer was, "We've given you a Republic, can you keep it?" The mission of synthisophy is to depolarize the Nation and to answer Franklin's question in the affirmative, "Yes, we can. 


\section{Review of Chapters 16 through 30}

\subsection{Chapter 16: Skinwalkers}

Table 1: Number of mass shootings in US

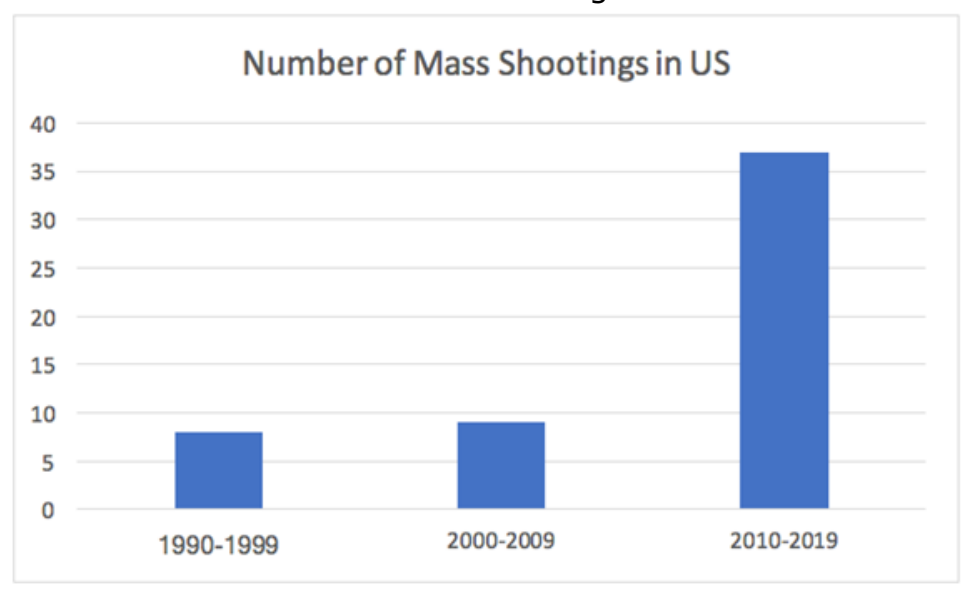

Source: Congressional Research Service

Note that from 1990 through 1999 there were 8 mass shootings; from 2000 through 2009 there were 9; from 2010 through 2019 there were 37. Why does it appear that over the last 10 years our society is generating a sharp increase in skinwalkers, a term from the Navajo Indian tribe for individuals committing murder and mayhem who have rejected almost all social bonds and attack people at their most vulnerable and unprepared? Perhaps it is because, as Junger (2016) stated in his book, Tribe, this "shows how completely detribalized this country has become." Our neurological genetic predisposition, the tribal and warrior ethos, all for 1 and 1 for all, is no longer relevant in modern life. As individuals in modern society it appears we are now very far from our evolutionary roots.

\subsection{Chapter 17: Modern Skinwalkers and Societal Cancer}

Modern Skinwalkers are individuals and corporations that harm or kill 1000s if not millions of people, but make millions if not billions of dollars for themselves doing it.

Metaphorically as presented in this chapter, fraud in Unemployment Benefits, Welfare, Medicare, Medicaid, and in the Defense, Financial and Pharmaceutical Industries started in their various subgroups (the cells), within a particular industry (an organ), and then metastasized and affected the whole country (the host). Metaphorically as presented in this chapter, fraud started within the Tobacco companies (the cells), within the tobacco industry (an organ), that has metastasized now affecting people in all countries around the world (the host).

\subsection{Chapter 18: Climate Change}

Here is a quote from the International Panel on Climate Change, 2014:

Many scenarios lead to substantial climate impacts, including direct harms to human and ecological well-being that exceed the ability of those systems to adapt fully. The planet as we know it is threatened. The energy supply sector is the largest contributor to global greenhouse gas emissions and therefore offers a multitude of options to reduce GHG emissions. But the stabilization of greenhouse gas concentrations at low levels requires a fundamental transformation of the energy supply system, including the long-term phase-out of unabated fossil fuel and their substitution by low-GHG alternatives.

Here are quotes from the International Panel on Climate Change, 2018: 


\section{Andre Houle \\ Synthisophy - Integrating the Wisdoms of History into Present Culture (Part 2 - Summary of Chapter 16 through 30)}

The decisions we make today are critical in ensuring a safe and sustainable world for everyone, both now and in the future. The next few years are probably the most important in our history. It's a line in the sand and what it says to our species is that this is the moment and we must act now. This is the largest clarion call from the science community and I hope it mobilizes people and dents the mood of complacency. There is nothing opaque about this new data. The illustrations of mounting impacts, the fast-approaching and irreversible tipping points are visceral versions of a future that no policy-maker could wish to usher in or be responsible for.

\subsection{Chapter 19: Smoke, Mirrors and Hot Air}

The following is a Summary Statement of The Climate Deception Dossiers, titled Documenting Fossil Fuel Companies' Climate Deception, written by Elliot Negin, Union of Concerned Scientists, Summer 2015.

Spanning nearly three decades, these documents reveal that the world's largest fossil fuel companies-BP, Chevron, ConocoPhillips, ExxonMobil, coal giant Peabody Energy, and Shellwere fully aware of the reality of climate change but continued to spend tens of millions of dollars to sow doubt and promote contrarian arguments they knew to be wrong. Taken together, the documents show that these six companies, in conjunction with the American Petroleum Institute (API) - the oil and gas industry's premier trade association-and a host of front groups, have colluded to intentionally deceive the public; their corporate officials have known for at least two decades that their products are harmful; and their disinformation campaign continues today-despite the fact that most of the companies now publicly acknowledge the reality of anthropogenic, or human-caused, climate change.

The American Petroleum Institute's 1998 Memo Presents a Roadmap for Climate Deception:

Global Climate Science Communications

Action Plan

Project Goal

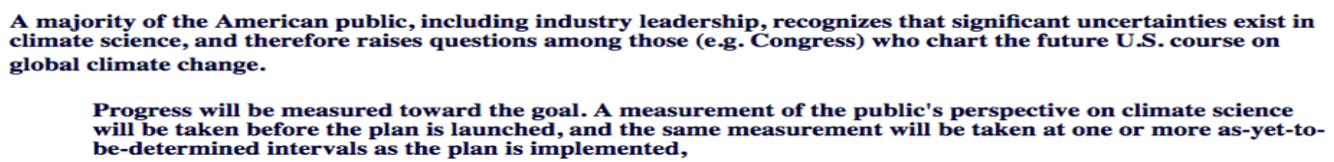

Victory Will Be Achieved When

- Average citizens "understand" (recognize) uncertainties in climate science; recognition of uncertainties becomes part of the "conventional wisdom"

- Media "understands" (recognizes) uncertainties in climate science

- Media coverage reflects balance on climate science and recognition of the validity of viewpoints that challenge the current "conventional wisdom"

- Industry senior leadership understands uncertainties in climate science, making them stronger ambassadors to those who shape climate policy

- Those promoting the Kyoto treaty on the basis of extent science appears to be out of touch with reality.

\section{Current Reality}

Unless "climate change" becomes a non-issue, meaning that the Kyoto proposal is defeated and there are no further initiatives to thwart the threat of climate change, there may be no moment when we can declare victory for our efforts. It will be necessary to establish measurements for the science effort to track progres

\section{Source: Global Climate Science Communications}

The Fossil Fuel Industry is another malignant cancerous Skinwalker that metaphorically started as particular companies (the cells), within a particular industry (an organ), that has metastasized now involving all nations and, and is the cause of climate change that is now impacting the entire earth (the host) at tremendous cost. The Fossil Fuel Industry is making billions of dollars with their deceit while killing their own causing global warming and climate change with increased $\mathrm{CO} 2$ levels in the atmosphere, which result in global temperature rise, 
warming oceans, shrinking ice sheets and glacial retreat, extreme weather events like hurricanes and droughts, and ocean acidification.

\subsection{Chapter 20: We are very far from our Genetic Roots}

As individuals and society it appears we are now very far from our evolutionarily and genetically selected, and now our neurologically hardwired roots:

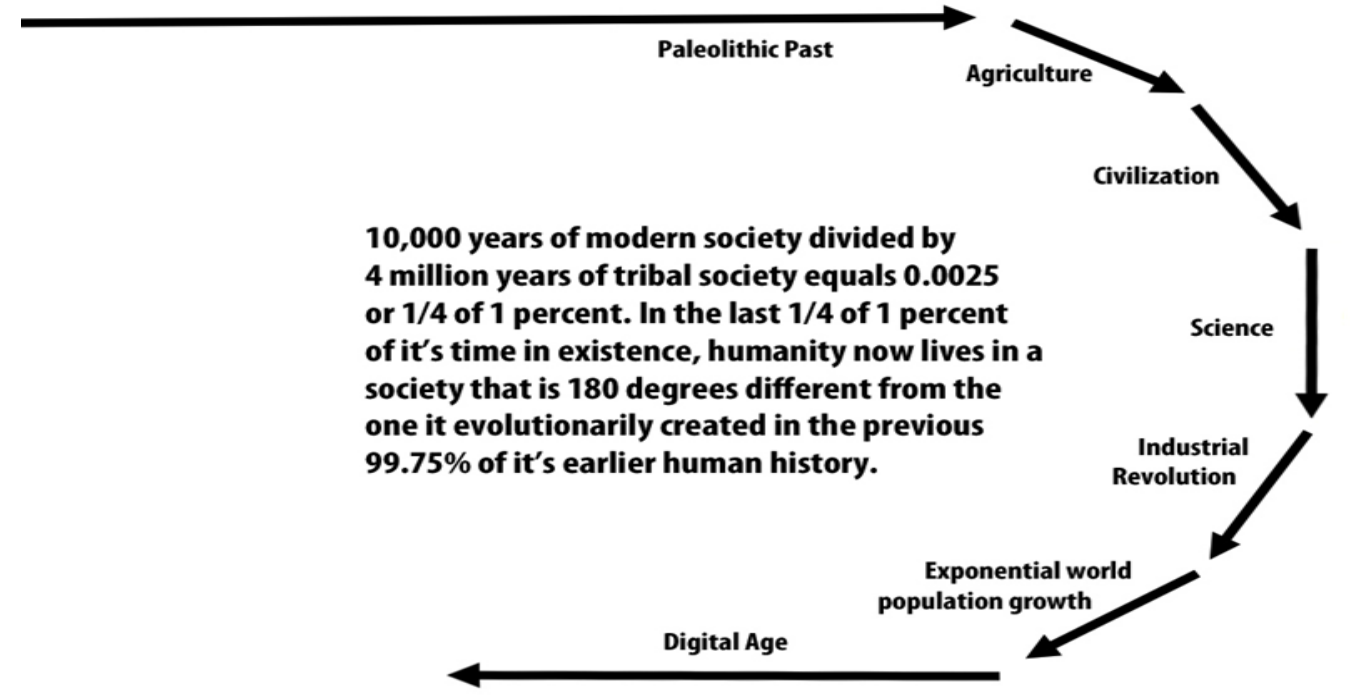

Figure 1: Neurologically hardwired roots Source: Synthisophy website

Each revolution results in 30 degrees of change in the direction of humanity

\subsection{Chapter 21: Sport, Gestalt and War}

The word tribe has been used recently in the news to describe our current political layout, saying $30 \%$ of the population still supporting Trump are devoted far Right, and $30 \%$ are devoted far Left, and each are using cognitive and confirmation bias and argumentative theory to support their tribal views. Apparently only $40 \%$ of the population may have a more centrist realistic political perspective, the other $60 \%$ are genetically, confirmationally, argumentatively and tribally biased to the Left and Right.

So is it our warrior ethos and sense of belonging to a tribe that now influences our neuroreality? Homo sapiens were able to dominate the world with their tribal and warrior ethos, now this warrior ethos and sense of belonging to a tribe overcomes reason and logic. That tribal instinct then creates different tribes within the whole country, the two main political tribes we have now are the Right and the Left, with sub-tribes as in the alt-Right and illiberal Left battling each other. Where's our neuroreality as a Nation to let this tribal polarization happen?

\subsection{Chapter 22: Fantasyland}

Fantasyland is a term used to describe one's perception of reality, one's neuroreality, when that perception is far from actual reality. The following are quotes from the book; Fantasyland, How America Went Haywire, a 500 Year History, by Kurt Andersen, 2017.

I've referred repeatedly to full Fantasyland and to events and phenomena (such as President Trump) that wouldn't have happened before it emerged. And, of course, the Internet: starting in 1995 everyone could browse the Web, so let's call 2000, the first year a majority of Americans were online, the unequivocal first year of full Fantasyland. 


\section{Andre Houle \\ Synthisophy - Integrating the Wisdoms of History into Present Culture (Part 2 - Summary of Chapter 16 through 30)}

Our circumstance doesn't seem altogether new. Fantasyland has been the norm for the run of humanity; the unusually rational and scientific centuries here and there along the way, like the last few, are exceptions. Dominant cultures have had their enlightenments and golden ages before, then returned to primitivism and murk.

\subsection{Chapter 23: Fantasy Has Become Reality}

In his book Fantasyland, Kurt Andersen has made a very powerful case for his theory that a significant portion of the present population has a perception of reality, a neuroreality, that is simply not true, that we are now in Fantasyland.

I would like to add to Andersen's Fantasyland theory that fantasy has become reality to a significant portion of the US population as he has applied it to the settlement of the New World over the last 500 years, to human evolution over the last 4 million years. Let's review earlier statements.

In the extraordinarily complex society of today, the instinctive cognitive bias, the resulting confirmation bias, that generated the argumentative theory and the tribal ethos, that then led by extension to the warrior ethos, may all very well be present in the 100 billion neurons in your brain helping to generate one's perception of reality, one's neuroreality. And as proposed by Andersen in Fantasyland, that neuroreality may not reflect true reality. It's in our genes. Our perception of reality, our neuroreality, has been in our genes since the advent of Australopithecus and cognitive bias 4 million years ago or perhaps much earlier, to Homo habilis and confirmation bias 3 million years ago, to Homo erectus and the argumentative theory 2 million years ago, all the while from there generating the tribal ethos resulting in the warrior ethos that led to Homo sapiens 300,000 years ago and their migration out of Africa 70,000 years ago to dominate the world, and to us today.

\subsection{Chapter 24: The Previous President and Neuroreality}

The neurorealities of Trump as described in this Chapter are quite far from actual reality. Consider earlier mentioned the neurorealities of Einstein in his theories of relativity, Charles Darwin and his theory of evolution and Francis Bacon's description of the scientific method of thinking. These are key perceptions of reality as they really exist, they are truth, and they are real. Let's call their perceptions neureal, in these areas Einstein, Darwin and Bacon are neurealists, they think neureally, their neurorealities are examples of neurealism and the neureal. As far as Trump's perceptions of reality as described here, his perceptions are unneureal, Trump is an unneurealists, he thinks unneureally, his neuroreality is an example of unneurealism and the unneureal. And as mentioned in Chapter 21, so is $30 \%$ of the current US population who are alt-Right and still adamantly support Trump.

\subsection{Chapter 25: The Same Unneurealism Exists on the Left}

The neurorealities of the illiberal Left as presented in this Chapter are quite far from actual reality. Consider earlier mentioned the neurorealities Albert Einstein, Charles Darwin and Francis Bacon. These are key perceptions of reality as they really exist, they are truth, and they are real. Let's call their perceptions neureal, in these areas Einstein, Darwin and Bacon are neurealists, they think neureally, their neurorealities are examples of neurealism and the neureal. As far as the illiberal Left's perceptions of reality as described here, they are unneureal, the illiberal Left are unneurealists, they think unneureally, their neurorealities are examples of unneurealism and the unneureal. And as mentioned in Chapter 21, so is $30 \%$ of the current US population who are adamantly illiberal Left.

In the extraordinarily complex society of today, the instinctive cognitive biases, the resulting confirmation bias, argumentative theory and the tribe mentality stoked by the warrior ethos 


\section{Andre Houle}

Synthisophy - Integrating the Wisdoms of History into Present Culture (Part 2 - Summary of Chapter 16 through 30)

may very well be present in the 100 billion neurons in our brain helping to generate someone's perception of reality, someone's neuroreality. And as proposed by Andersen in Fantasyland, as well as by Powers in The Silencing, and as expanded upon by myself, that neuroreality may not always reflect true reality, it may be unneureal. It's in our genes, it's been in our genes for a very long time.

\subsection{Chapter 26: Yin and Yang}

Note that with much of the historic perspective in this book being of Western origins, perhaps there are some things that the West could learn from the longest lasting civilization on the planet, China and the Far East, which is $\mathbf{5 0 0 0}$ years old and is the only ancient civilization that still continues today.

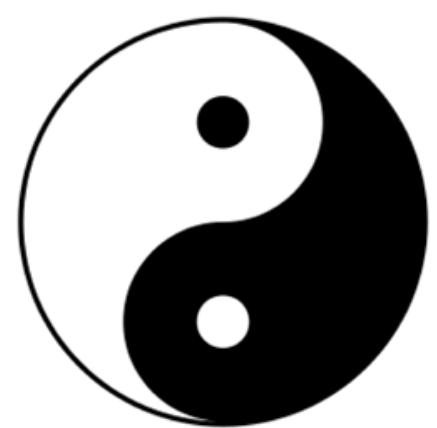

Figure 2: Yin and Yang

In Chinese philosophy, yin and yang (陰陽 yīnyáng, literally "dark-bright", "negative-positive") describe how seemingly opposite or contrary forces may actually be complementary, interconnected, and interdependent in the natural world, and how they may give rise to each other as they interrelate to one another. Many tangible dualities (such as light and dark, fire and water, male and female, left and right, black and white) are thought of as physical manifestations of the duality symbolized by yin and yang.

So let's try and get away from illiberal-Left and alt-Right polarization, move towards the more rational Center, integrating aspects of both Yin and Yang (Left and Right) so our society resembles more the functional tribe from whence we genetically and evolutionarily came.

\subsection{Chapter 27: The Upside-down Bell Curve}

Remember the regular bell curve:

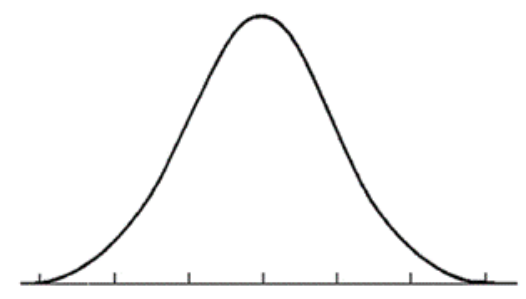

Figure 3: Regular bell curve

Let's look at the progression of the politically engaged graphs over the past 25 years: 


\section{Polarization Surges Among the Politically Engaged \\ Distribution of Democrats and Republicans on a 10-item scale of political values, by level of political engagement}

\section{Among the politically engaged}
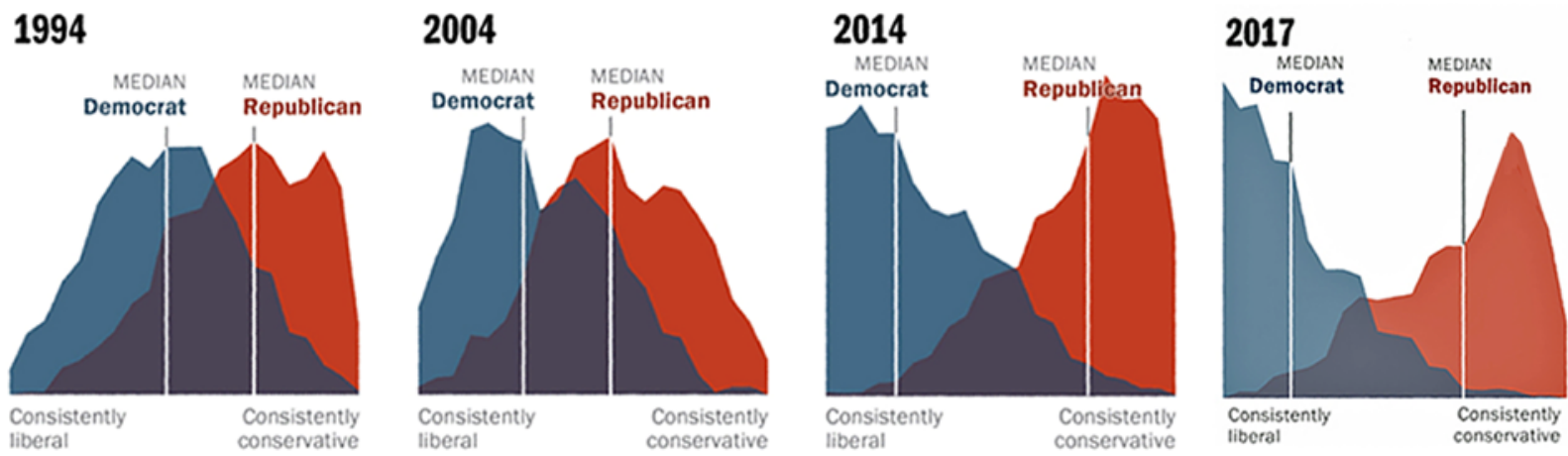

Figure 3: Polarization surges among the politically engaged

Source: Political Polarization

Note in 1994 there is no split in the curve between the Left and the Right, in 2004 we can see a split starting, by 2014 we can see an increase in polarization as the upside-down bell curve shows itself, and by 2017 the upside-down bell curve becomes prominent. These graphs show us the polarization of the Left and Right and the upside-down bell curve now present in the USA. If a bell curve is considered normal, why do we as a society among the politically active and influential have an upside-down bell curve, is that abnormal? Why are we so polarized? The answer lies in the human brain and neurological evolution. It's in our genes, it's been in our genes for a very long time: cognitive bias probably developing over the course of late mammalian evolution and present in Australopithecus; to confirmation bias in Homo habilis; to the tribe and argumentative theory, where truth doesn't matter, winning the argument and gaining power does in Homo erectus; all the while generating the tribal ethos resulting in the warrior ethos that led Homo sapiens out of Africa 70,000 years ago to dominate the world. Our genetically evolved and present cognitive, confirmation, tribal and argumentative biases shape our polarized perceptions of the world around us, and our warrior ethos finds others of similar mind to battle the opposing party. Do we have to be this polarized? Can individual human consciousness be aware of this predisposition and keep it in check, putting value in moderation, reason and truth? Can your neuroreality be neureal rather than unneural? Ben Franklin addressed that question after the Constitutional Convention: "We've given you a republic, can you keep it?" Perhaps if we depolarize, get back to the normal bell curve, become more neureal, and become more centrist as a Nation, the answer will be yes.

\section{Chapter 28: Politics and Thesis 4}

I'd like to make a comment here about the unneurealism of the alt-Right and illiberal Left as mentioned in chapters 24 and 25, as it relates to the discussion of religion in Chapter 10 and 15, particularly Thesis 2 - Realigion. Note that Religion in the United States has been on the decline for the past 50 years. Could this religious neurological void be filled with a zealous devotion to politics? Perhaps politics has taken the place of religion, particularly among the unneureal alt-Right and Illiberal-Left. Recall the old adage, never talk about politics or religion? Thesis 4: Perhaps politics on the alt-Right and illiberal Left has become their religion.

Before we delve into Chapter 29 and address various political issues in the US, let's take a look at the opinion of Zeynep Tufekci in 2018, as she expressed in her article in the New York Times, March 2018, titled: YouTube, the Great Radicalizer. This article sums up quite clearly the impact of the Digital Revolution on society today: 


\section{Andre Houle \\ Synthisophy - Integrating the Wisdoms of History into Present Culture (Part 2 - Summary of Chapter 16 through 30)}

It seems as if you are never "hard core" enough for YouTube's recommendation algorithm. It promotes, recommends and disseminates videos in a manner that appears to constantly up the stakes. Given its billion or so users, YouTube may be one of the most powerful radicalizing instruments of the 21 st century.

This is not because a cabal of YouTube engineers is plotting to drive the world off a cliff. A more likely explanation has to do with the nexus of artificial intelligence and Google's business model. (YouTube is owned by Google.) For all its lofty rhetoric, Google is an advertising broker, selling our attention to companies that will pay for it. The longer people stay on YouTube, the more money Google makes.

What keeps people glued to YouTube? Its algorithm seems to have concluded that people are drawn to content that is more extreme than what they started with - or to incendiary content in general.

What we are witnessing is the computational exploitation of a natural human desire: to look "behind the curtain," to dig deeper into something that engages us. As we click and click, we are carried along by the exciting sensation of uncovering more secrets and deeper truths. YouTube leads viewers down a rabbit hole of extremism, while Google racks up the ad sales.

This state of affairs is unacceptable but not inevitable. There is no reason to let a company make so much money while potentially helping to radicalize billions of people, reaping the financial benefits while asking society to bear so many of the costs.

\section{Chapter 29: What can we do?}

With synthisophy in mind.... what can we do to depolarize the Nation?

Recall that hominids that cooperated with one another - and punished those who didn't - must have outfought, outhunted and outbred everyone else. Over millions of years, this genetically evolved and biologically selected tribal ethos resulting in the exit of Homo sapiens with the extension of the warrior ethos out of Africa 70,000 years ago, led to the dominance of this human species and the extinction of others. This ethos resulted in our becoming the dominant and only human species on the planet and is still hardwired into our evolutionary genetic consciousness.

So maybe if we understand that these evolutionarily developed instinctive cognitive biases, the resulting confirmation biases, and the argumentative theory stoked by the tribal and warrior ethos may very well be present in the 100 billion neurons in our brain generating our perception of reality, our neuroreality, which as proposed by Andersen in Fantasyland, Powers in The Silencing, and expanded upon by myself, may not always reflect true reality, it may be unneureal. It's in our genes, it's been in our genes for a very long time. So let's take a step back, try and detach ourselves from this genetic predisposition, take a deep breath and try and be a bit more rational rather than emotional in our political positions and discussions, listen, seek truth rather than argument, and reduce the amount of polarization and vitriol present in our society. Restated, let's be politically active, synthisophic and neureal.

So what can we do to depolarize the Nation?

Take Action: Participate in the democratic process as suggested in this Chapter, be an informed citizen, get involved in a cause that will better society. We need an active and informed citizenry. Consider classical times in ancient Greece: At any particular point in time, not just on election day, an estimated $75 \%$ of voters were participating in government in one form or another. Consider what Thomas Jefferson said: "The people can not be all, \& always, well informed, the 
Andre Houle

Synthisophy - Integrating the Wisdoms of History into Present Culture (Part 2 - Summary of Chapter 16 through 30)

part which is wrong [. . .] will be discontented in proportion to the importance of the facts they misconceive. If they remain quiet under such misconceptions it is a lethargy, the forerunner of death to the public liberty." Abraham Lincoln said, "If we falter and lose our freedoms it will be because we destroyed ourselves." So Take Action on one of the 30 political issues discussed in this Chapter, or any of the 100s of other issues you think are important to you, society and humanity.

\section{Chapter 30: Our Future}

Let's look at an exponential graph showing the rate of evolutionary and societal change over time using earlier presented data:

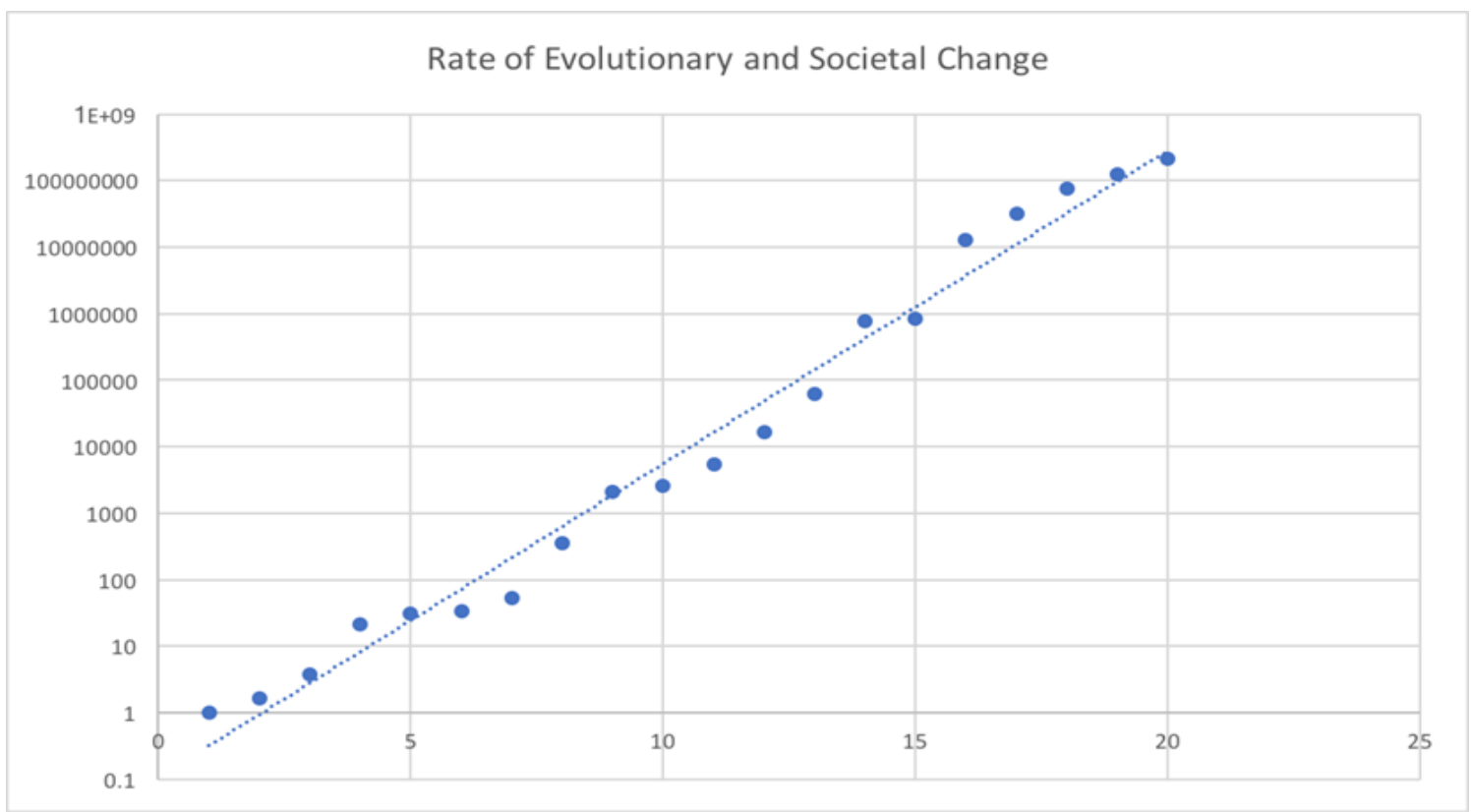

Figure 4: Rate of evolutionary and societal change

Source: Synthisophy website

The above graph looks quite similar to the graph below generated for transistor counts in computers over time shown below:

\section{Transistor Count}

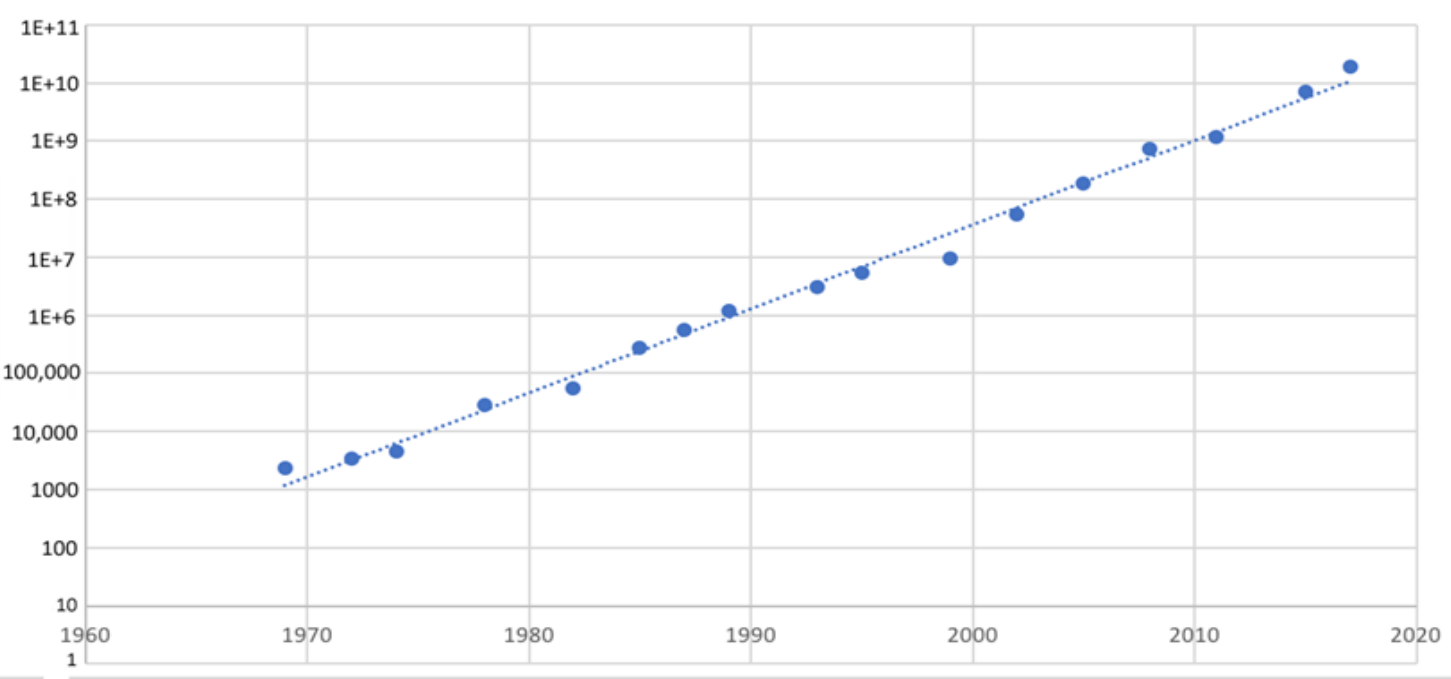

Figure 5: Transistor count 


\section{Andre Houle \\ Synthisophy - Integrating the Wisdoms of History into Present Culture (Part 2 - Summary of Chapter 16 through 30)}

Source: ourworldindata website

What does this logarithmic similarity between evolutionary and societal change over the last 3.8 billion years and the computer transistor count in the last 50 years mean? At this point in time this similarity may mean that we are in the early stage of huge societal changes as a result of the digital revolution, and that it may be in our best interest to become less polarized and more rational in order to best choose our destiny as a society. We should heed Ben Franklin's question: "We've given you a Republic, can you keep it?" Yes, and to do so we need to be politically active, synthisophic and neureal.

That said, the convergence of the human/societal evolution and the transistor count/digital revolution may at some point in the not too distant future reach the point of singularity, when computers and artificial intelligence equal that of the human brain, after which computers will then surpass human intelligence. As stated earlier in Thesis 3 Chapter 15, note that computers can process and correlate billions of bits of information per second, whereas the human brain at the consciousness level is very limited in that capacity. Also note that the human brain can integrate many pieces of related information and create new and original ideas, not just correlates.

Looking at Bloom's taxonomy, computers can remember, understand, apply, analyze (correlate) and even evaluate information. But at the top of Bloom's taxonomy, only the human brain can create new and original ideas integrating many pieces information from a wide variety of historic sources and come up with something completely new and of possible societal value. Restated, computers cannot and will not be able to synthisophize, integrate the wisdoms of history into present culture. Only we, the people, can do that.

\section{References}

- Negin, E. (2005). Documenting Fossil Fuel Companies' Climate Deception. Catalyst, Union of Concerned Scientists.

- Houle, A. (1995). The United States of America, A Motif for the Individual and Society. SKOLE, the Journal of Alternative Education.

- Houle, A. (2021). Synthisophy. Available at http://www.synthisophy.com/.

- Intergovernmental Panel on Climate Change, (2014). Climate Change 2014, Mitigation of Climate Change. CrossRef

- Intergovernmental Panel on Climate Change., (2018). Special Report on Global Warming of $1.5^{\circ} \mathrm{C}$.

- Junger, S. (2016). Tribe, On Homecoming and Belonging. New York, NY: Twelve Hatchett Book Group.

- $\quad$ Kurt Andersen, (2017). Fantasyland, How America Went Haywire, a 500 Year History. New York, NY: Random House.

- Pew Research Center. (2017). Political Polarization, 1994-2017.

- Vanderbilt University, Center for Teaching. n.d. Bloom's Taxonomy.

- Zeynep Tufekci. (2018). YouTube, the Great Radicalizer. New York Times. 